\title{
Organizational Knowledge and Skills, Managerial Attitudes and Performances regarding Foods Safety in food Manufacturing Firms in Thailand
}

\author{
Chanchana Siripanwattana ${ }^{1}$, Achara Chandrachai ${ }^{2}$ and Suwimon Keeratipibul ${ }^{3, *}$ \\ ${ }^{\mathbf{1}}$ Technopreneurship and Innovation Management \\ Graduate School, Chulalongkorn University, Bangkok, Thailand \\ ${ }^{2}$ Faculty of Commerce and Accountancy, \\ Chulalongkorn University, Bangkok, Thailand \\ ${ }^{3}$ Faculty of Science, \\ Chulalongkorn University, Bangkok, Thailand \\ ${ }^{*}$ Corresponding author's email: Suwimon.K [AT] chula.ac.th
}

\begin{abstract}
The aim of this study was to determine the differences in organizational knowledge and skills, managerial attitudes, and performances (KAP) of food safety system among food manufacturing firms in Thailand. In addition, it also aimed to identify the factors that affect food safety performance the most. The study used stratified random sampling based on the number of firms, firm size and location. A total of 326 medium and large-sized food manufacturers located in the Bangkok metropolitan area and four different parts of Thailand responded. The statistical methods used for data analysis included descriptive analysis, ranking analysis, correlation analysis, and multiple regression analysis. The results showed that the characteristics of the firms, such as size, age, export orientation, and foreign ownership did not significantly ( $p>0.05)$ affect their food safety performance. The results of the logistic regression analysis showed that the firms' organizational knowledge and skills and managerial attitudes were significantly $(p<0.05)$ and positively associated with their food safety performance. The high level of organizational knowledge and skills and positive managerial attitudes regarding food safety management system were crucial for maintaining a high level of food safety system performance.
\end{abstract}

Keywords---- Food Safety, Food Manufacturing Firms, Organizational Knowledge, Managerial Attitudes, Performances, Thailand

\section{INTRODUCTION}

The World Health Organization [1] estimated that 600 million people on the planet fall ill and more than 420 thousand die every year from diarrheal diseases, the majority of which are foodborne. The non-awareness of food hygiene can be a major cause of food poisoning. However, a number of researchers have suggested that the lack of food hygiene knowledge and applying of such knowledge played an important role in food hygiene protection [2] [3] [4] [5].

However, several studies have reported non-significant positive correlation of food safety knowledge and skills gained from the training, food safety attitudes, food safety practice, and food safety performance and that only knowledge and skills do not always result in desirable changes in food safety performance [7] [8] [9]. A number of reasons have been proposed for the fact that knowledge and skills factors have not consistently created more desirable food safety practices; including, highly inhibitory attitude towards food safety, underestimated perception of risk, inadequate supplies and facilities due to lack of managerial support, and poor enthusiasm [0] [9] [10] [11] [12] [13].

Behavior can be influenced by attitudes. A positive attitude towards food safety significantly determines high levels of conformation to food safety standards [14] [15]. The engagement of top management is mainly dependent on managerial attitudes. Behavior is believed to be the result of influential factors and repetition. The association between attitudes, behaviors, and outcomes are complicated. According to Ajzen and Fidhbein [14], a large number of studies have indicated that there are significant correlations between attitudes and behaviors [2] [4] [5] [7] [12] [15] [16] [17]. People's attitudes develop because of direct experience, belief, culture, stimuli, and environment. Moreover, attitudes are delivered in the forms 
of cognitive components (information, belief and understanding), affective components (emotion and sensation), and behavioral components (propensity to respond). The theory of perceived behavior control suggests the way an individual tends to behave depends on his or her belief that it is good and can be done. In other words, perceived behavioral control denotes the idea that an individual's decision to perform because of their awareness of the degree of control over their behavior. Hence, when a manager believe that food safety is very important and he or she is responsible for it (he or she is a crucial part), he or she would support and put all efforts to fulfil the food safety system requirements.

The combination of abundant natural resources, huge investment in food research and development, high availability of quality workforce, and the compliance to international quality standards have all helped Thailand to aim to become the "kitchen of the world." Thailand is one of the world's largest producers of rice, sugar, seasonings and a variety of frozen livestock products and canned fishery products. Thailand is a crucial hub of food production for many countries because of its biodiversity, new technology investment, and the productivity of its agricultural sector. Moreover, the Thai government has launched policies supporting food production with highest standard of food safety and quality. Its high potential and key fundamentals have made Thailand the preferred production and distribution center for the food industry. According to Bank of Thailand [18], the food industry was the second largest contributors to Thailand's economy, accounting for $23 \%$ of the nation's Gross Domestic Product (GDP). In 2016, the value of Thai food exports increased by approximately $6 \%$ to reach up to USD 27 billion and make Thailand to a prominent player on the global stage.

Food safety is among the most important aspects to control to enjoy a high competitive advantage as a food export nation. Most management systems intend to find new ways to reduce food contamination; for example by developing new methods of traceability, new technologies, and tools for risk management. The food supply chain is long from farm through agricultural ingredients additives and food manufacturing plant to table including the home, street vendors and restaurants. Inefficient strict controls with regards to food preparation, storage and display may be foremost in food-borne disease. In order to retain its position as the world's major food exporter, the Thai government has demanded that farmers and exporters understand the procedures of Good Agricultural Practices (GAP), the processing for food using Hazard Analysis and Critical Control Point (HACCP) and Good Manufacturing Practices (GMP) to reduce pollution of food products. This paper focuses on the link in the food supply chain that depicts the food processing processes in the factory with the importance of the value chain. The Thai government and factory management have been emphasizing training of farmers, factory employees, and scientists to improve their knowledge and skills to improve the eradication of poor food handling and manufacturing practices. Identifying the contribution of food to the Thai economy and the livelihood of Thai people, food safety can be defined as an essential tool to enhance Thailand's global export competitiveness. However, there is considerable evidence to indicate that good knowledge and skills can help but cannot completely eradicate the problem of food safety because food safety implementation and its performance are significantly contingent on other factors including firms' characteristics.

Consequently, foodborne illness has caused considerable economic and social burdens in terms of monetary and nonmonetary costs. Food borne diseases have caused severe private and public health problems for families and communities in both developed and developing countries. In Thailand, data from the Ministry of Public Health [28] indicated that more than 47,000 food poisoning cases occurred during the first five months of 2016 due to foodborne disease and its number was rising among the type of illness of Thai citizen. Training in food hygiene plays an important role for food workers and food controlling system for example in Europe. Moreover, the Regulation 852/2004 mandates all food handlers should have food hygiene training. In Thailand, food manufacturing firms are required to provide their food workers with knowledge and skills in food hygiene. However, the efficiency and effectiveness of the training system and implementation are still questionable.

Pitchiler et al. [16] stated that in Europe, $31 \%$ of foodborne illness was linked to catering in restaurants, cafes, pubs, bars, and hotels while $17 \%$ was associated with schools, kindergartens, and residential institutions. Other foodborne illnesses were associated with food manufacturing firms. In Thailand, there are no accurate data on this issue. However, food manufacturing firms usually have a large production system owing to the law of economies of scale. Therefore, they are likely to generate big negative impacts on people's public health because of contamination of large scale production regardless of how well and how long they have implemented food safety system in their firms. Hence, this study focuses on medium and large food manufacturing firms. To the best knowledge of the authors, there is no formal study relying on organizational knowledge and skills, managerial attitudes, and performances models of medium and large-scale food manufacturing firms in Thailand. Therefore, the principle analysis of this study is the organization. Hence, the objectives of this study were to understand the effects of organizational knowledge and skills, managerial attitudes, and performances (KAP) of food safety system among food manufacturing firms in Thailand and to detect the major elements determining food safety performance. 


\section{METHODS AND INSTRUMENTS}

From October 2016 to June 2017, the characteristics, organizational knowledge and skills, managerial attitudes, and performances of food safety systems of food manufacturing firms were examined using a questionnaire survey. The questionnaire comprised of mainly multiple-choices questions that were formulated based on this KAP model in combination with characteristic organizational elements. Each questionnaire was answered by a chief quality assurance officer of the food manufacturing firm taking part in the survey. An identical approved questionnaire was delivered to 715 medium and largesized food manufacturing firms across Thailand. There were more than 4,000 medium and large-sized food manufacturing firms formally registered in the Bangkok metropolitan area and four other parts of Thailand. Stratified random sampling was based on the number of firms, firm size, and location. Three hundred and forty five firms completed questionnaires were returned of which three hundred and twenty six questionnaires were considered qualified for inclusion. Data were analyzed using SPSS software 17.0 version. Description analysis and ranking analysis were executed in order to demonstrate each factor in the study. Pearson correlation analysis was performed to assess differences in parametric elements and to analyze the association between organization - related data, organizational knowledge, managerial attitudes, and performances. Multiple regression analysis was carried out to explore the systematic relationship between organizational food safety performances (dependent variable) and other elements (independent variables) including organizational knowledge and skills, managerial attitudes, and firms characteristics (firm size, firm age, export orientation, and foreign ownership). The firms in this research had only two sizes which were "medium size" (sales between 50 and 199.999 million) and "large size" (sales more than or equal to 200 million). The differences in this study were determined to be statistically significant at $p<0.05$ in all analyses.

The objectives of the questionnaire and its instructions verbally were explained to all respondents. All completed questionnaires were assigned a code enabling formal identification while keeping the respondents anonymous, which protected the right of respondents in all aspects. Moreover, the study was approved by the research committee of Technopreneurship and Innovation Management Program (TIP) at Chulalongkorn University.

The first part of questionnaire was composed of the organizational knowledge and skills regarding food safety in a workplace. There were 12 close-ended questions relating to food safety training, manual inputs, revision program, experiences, controlling systems, and 'buddy' system for new food handlers. All questions dealt with the level of knowledge, skills, and experiences of food manufacturing firms. At each firm, the chief food assurance officer was requested to show their level of agreement with each statement regarding organizational food safety knowledge and skills using a 7 point-Likert scale. Possible answers ranged from extremely agree (7), strongly agree (6), agree (5), not sure (4), disagree (3), strongly disagree (2), and extremely disagree (1).

The second part of the questionnaire comprised of managerial attitudes towards food hygienic measures. There were 7 close-ended questions relating to equipment support, willingness to support food safety systems, food safety engagement, and food safety risk perception. Seven questions regarding managerial attitudes towards food safety system were also created. The chief food assurance officers at each firm were requested to show their level of agreement to each statement using the 7 point-Likert scale used in the first part.

There were 7 close-ended questions relating to organizational food safety performance in the third part of the questionnaire. Chief food assurance officer at each firm was requested to show their level of agreement to each statement regarding entire picture of organizational food safety performances using the 7 point-Likert scale used in the first two parts. They included firms' possession of food safety standard ( e.g. GMP, HACCP, and ISO22000), the decline of customer complaints regarding food hygiene, customer satisfaction, the level of competitive advantages compared to their rivals, and increases in the quality of their delivery system. In addition, the final part of the questionnaire consisted of questions regarding organizational characteristics or the firm - related data, such as the age of the firm, firm size, export orientation/foreign exports, and foreign ownership/affiliation.

The questionnaire was designed to elicit data about the characteristics of the firm that were related to organizational knowledge and skills, managerial attitudes, and performances regarding food safety issues. Validity and clarity of the method was obtained from food scientists and food safety experts in several universities. The pre-test of the questionnaire conducted on the basis of simple random sampling technique to guarantee objectivity and clarity of participants' interpretation. A prestudy of this KAP model on 50 additional qualified firms on a pilot project was conducted to determine the reliability of each question with Cronbach's Alfa coefficient exceeding 0.80. By using item analysis, some questions in this study were revised to enhance their quality. The questionnaire was peer-reviewed and pilot-tested. Multiple regression analysis was used to test KAP model which had the organization as their unit of analysis, this was done to pinpoint variables influencing organizational food safety performance and the results are presented in the study. 


\section{RESULTS AND DISCUSSION}

This study evaluated organizational knowledge and skills, managerial attitudes, and food safety performance of food manufacturing firms of medium and large size located in Thailand. A total of 326 valid questionnaires were obtained with a $48.25 \%$ response rate. The questionnaire reliability was tested and the Cronbach's alpha values for each question were in acceptable range (equal to or exceeding 0.85 ).

Table 1: Distribution of characteristics of the food manufacturers who responded to the questionnaire

\begin{tabular}{|l|c|c|}
\hline \multicolumn{1}{|c|}{ Variables } & Mean & Standard Deviation \\
\hline Firm size (sale per year) & $267.30(\mathrm{~m})$ & 60.22 \\
\hline Medium size $(50 \mathrm{~m}<=$ Sale $<200 \mathrm{~m})$ & $177(54.3 \%)$ & - \\
\hline Large size $($ sale $>=200 \mathrm{~m})$ & $149(45.7 \%)$ & - \\
\hline Firm Age & $22.16($ years $)$ & 12.10 \\
\hline Foreign trade orientation (foreign trade) & $27.98(\mathrm{~m})$ & - \\
\hline Exporting firms & $186(57.1 \%)$ & - \\
\hline Non-exporting firms & $140(42.9 \%)$ & 3.63 \\
\hline Foreign ownership & $12.43(\%)$ & - \\
\hline Firms with 100\% domestic ownership & $212(65.0 \%)$ & - \\
\hline Firms with foreign ownership & $114(35.0 \%)$ & \\
\hline
\end{tabular}

Table 2: Organizational knowledge and skills (“K \& S") statements

\begin{tabular}{|c|c|c|c|}
\hline Items & “K \& S" Statements & $\begin{array}{l}\text { Mean Score } \\
\text { (Standard } \\
\text { Deviation) }\end{array}$ & Rank \\
\hline K1 & $\begin{array}{l}\text { The firm has knowledgeable and skillful } \\
\text { food safety experts. }\end{array}$ & $\begin{array}{c}5.54 \\
(1.1214)\end{array}$ & 11 \\
\hline K2 & $\begin{array}{l}\text { The firm has a number of food safety } \\
\text { trainings for workers. }\end{array}$ & $\begin{array}{c}5.60 \\
(1.1475)\end{array}$ & 8 \\
\hline K3 & $\begin{array}{l}\text { The firm has formal food safety manual } \\
\text { documents for workers to follow. }\end{array}$ & $\begin{array}{c}5.58 \\
(1.224)\end{array}$ & 10 \\
\hline K4 & $\begin{array}{l}\text { The firm has a regular meeting about food } \\
\text { safety issues. (Adapted from Wikstrom and } \\
\text { Norman, 1994) }\end{array}$ & $\begin{array}{c}5.59 \\
(1.170)\end{array}$ & 9 \\
\hline K5 & $\begin{array}{l}\text { The firm has a long term project for } \\
\text { continuous improvement in food safety } \\
\text { system. (Adapted from Pornlert et al., 2009) }\end{array}$ & $\begin{array}{c}5.66 \\
(1.179)\end{array}$ & 5 \\
\hline K6 & $\begin{array}{l}\text { The firm has a lot of workers with high level } \\
\text { of knowledge and skills in food safety. }\end{array}$ & $\begin{array}{c}5.45 \\
(1.219)\end{array}$ & 12 \\
\hline K7 & $\begin{array}{l}\text { The firm has an excellent food safety } \\
\text { management system. }\end{array}$ & $\begin{array}{c}5.61 \\
(1.128)\end{array}$ & 7 \\
\hline K8 & $\begin{array}{l}\text { The firm has long duration experiences in } \\
\text { food safety issues. }\end{array}$ & $\begin{array}{c}5.71 \\
(0.994)\end{array}$ & 3 \\
\hline K9 & $\begin{array}{l}\text { Food safety control and assessment is one of } \\
\text { the firm's strength. }\end{array}$ & $\begin{array}{c}5.71 \\
(1.080)\end{array}$ & 3 \\
\hline K10 & $\begin{array}{l}\text { The firm has been conducting food safety } \\
\text { and food quality assurance at the highest } \\
\text { level. }\end{array}$ & $\begin{array}{c}5.78 \\
(1.071)\end{array}$ & 2 \\
\hline K11 & $\begin{array}{l}\text { New workers always receive efficient and } \\
\text { effective food safety training. }\end{array}$ & $\begin{array}{c}5.79 \\
(1.093)\end{array}$ & 1 \\
\hline K12 & $\begin{array}{l}\text { The firm provides new workers with } \\
\text { adequate knowledge and skills to cope with } \\
\text { food safety problems. }\end{array}$ & $\begin{array}{c}5.62 \\
(1.022)\end{array}$ & 6 \\
\hline \multicolumn{2}{|r|}{ Total knowledge and skills average score } & \multicolumn{2}{|c|}{5.636} \\
\hline
\end{tabular}


The firms' characteristics, such as size, age, export orientation, and foreign ownership, were collected during the study. These four main types of firms' characteristics were continuously variable. The data reflected the fact that respondents with medium size, with some export, and were $100 \%$ Thai ownership dominated the group. The average age of the firm was 22.16 years. $57.1 \%$ of respondents had export trading with partners and their average export sales were 27.98 million baht. The foreign ownership of the respondents ranged from 0 to $100 \%$ with the average foreign ownership of $12.43 \%$

There were 12 statements (K1-K12) related to organizational knowledge and skills ("K \& S" statements) that were used in this study. Each statement underwent food safety experts and was also pilot-tested to ensure its validity, understandability, and reliability. Cronbach's alpha values all exceeded 0.90 which indicated the high level of reliability of the "K" questions. In addition, Kolmgorov-Smirnov values of each "K" question surpassed 0.05 indicating normal distribution. The scores of these $\mathrm{K} \& \mathrm{~S}$ statements ranged from 5.45 to 5.79 which indicated that the mean score of each statement was not significantly different $(p=0.05)$ from an overall mean score of 5.636. The overall mean score of knowledge and skills was high because the respondents were from medium and large-sized firms that were likely to have more resources, higher competencies, and longer experiences regarding food safety issues. The highest-score (5.79) was for the K \& S Statement "New workers always receive an efficient and effective food safety training."; whereas, the lowest (5.45) was for "The firm has a lot of workers with high level of knowledge and skills in food safety."

Table 3: Managerial Attitudes (“A”) statement towards food safety system

\begin{tabular}{|c|c|c|c|}
\hline Items & "A" Statements & $\begin{array}{c}\text { Mean Score } \\
\text { (Standard Deviation) }\end{array}$ & Rank \\
\hline$\overline{\mathrm{A} 1}$ & $\begin{array}{l}\text { Top management is willing to support all equipment } \\
\text { and necessary resources in food safety management } \\
\text { system. }\end{array}$ & $\begin{array}{c}5.81 \\
(1.011)\end{array}$ & 5 \\
\hline A2 & $\begin{array}{l}\text { Top management is more than happy to manage with } \\
\text { food safety as priority. }\end{array}$ & $\begin{array}{c}5.84 \\
(.998)\end{array}$ & 4 \\
\hline$\overline{\mathrm{A} 3}$ & $\begin{array}{l}\text { Top management always feels that food safety is very } \\
\text { crucial. }\end{array}$ & $\begin{array}{c}6.02 \\
(.973)\end{array}$ & 1 \\
\hline A4 & $\begin{array}{l}\text { Top management is satisfied and very proud of } \\
\text { complying with food safety rules and regulations. }\end{array}$ & $\begin{array}{c}5.98 \\
(1.009) \\
\end{array}$ & 3 \\
\hline A5 & $\begin{array}{l}\text { Top management always feels that food safety is one } \\
\text { of the most important factors in food businesses. }\end{array}$ & $\begin{array}{c}6.02 \\
(1.007) \\
\end{array}$ & 1 \\
\hline A6 & $\begin{array}{l}\text { Top management always perceives that their } \\
\text { engagement is very necessary for food safety } \\
\text { performance. }\end{array}$ & $\begin{array}{c}5.66 \\
(1.102)\end{array}$ & 7 \\
\hline A7 & $\begin{array}{l}\text { Top management is happy to be a good role model } \\
\text { regarding food safety issues. }\end{array}$ & $\begin{array}{c}5.74 \\
(1.140)\end{array}$ & 6 \\
\hline & Total attitude average score & \multicolumn{2}{|c|}{5.86} \\
\hline
\end{tabular}

There were 7 valid statements (A1-A7) related to managerial attitudes ("A" statements) used in this study. All Cronbach's alpha values for "A" statements were more than 0.90 indicating significantly $(p=0.05)$ higher level of reliability of these " $\mathrm{A}$ " statements. Kolmgorov-Smirnov values of each "A" statement surpassed 0.05 indicating normal distribution. The scores of these "A" statements ranged from 5.66 to 6.02 which indicated that the mean score of each statement was not significantly different $(p=0.05)$ and the overall mean score was high at 5.86. The results indicated that medium and large-sized respondents had a good perception of their managerial attitudes towards food safety management system. The two "A" Statements that had the joint highest score (6.02) were "Top management always feels that food safety is one of the most important factors in food businesses." and "Top management always feels that food safety is very crucial." However, the "A" statement with lowest score (5.66) score was "Top management always perceives that their engagement is very necessary for food safety performance." 
Table 4: Organizational food safety performances

\begin{tabular}{|c|l|c|c|}
\hline Items & \multicolumn{1}{|c|}{ "P" Statements } & $\begin{array}{c}\text { Mean Score } \\
\text { (Standard Deviation) }\end{array}$ & Rank \\
\hline P1 & $\begin{array}{l}\text { The firm has received a number of food safety standards, } \\
\text { such as GMP. HACCP, ISO22000, and BRC. }\end{array}$ & $\begin{array}{c}6.17 \\
(1.069)\end{array}$ & 6 \\
\hline P2 & $\begin{array}{l}\text { Customers' complaints regarding food safety declined } \\
\text { continuously in the past 3 years. }\end{array}$ & $\begin{array}{c}5.55 \\
(1.219)\end{array}$ & 7 \\
\hline P3 & $\begin{array}{l}\text { The rejection on delivered products declined continuously } \\
\text { in the past 3 years. }\end{array}$ & $\begin{array}{c}4.74 \\
(1.757)\end{array}$ & 5 \\
\hline P4 & Customer satisfaction in on the rise in the past 3 years. & $\begin{array}{c}5.58 \\
(1.022)\end{array}$ & 2 \\
\hline P5 & $\begin{array}{l}\text { The firm has strongly fulfilled the food safety system and } \\
\text { its implementation. }\end{array}$ & $\begin{array}{c}5.78 \\
(1.063)\end{array}$ & 5.72 \\
\hline P6 & $\begin{array}{l}\text { The firms' food safety management system is in the good } \\
\text { shape that leaves its competitors behind. (Adapted from } \\
\text { Pornlert et al., 2009) }\end{array}$ & $\begin{array}{c}5 \\
(1.107)\end{array}$ \\
\hline P7 & $\begin{array}{l}\text { In overall picture, the firm has an excellent competency in } \\
\text { managing the food safety system. }\end{array}$ & $\begin{array}{c}5.70 \\
(1.057)\end{array}$ \\
\hline
\end{tabular}

Performance ("P") statements consisting of 7 expert-approved and pilot-test sentences (P1-P7) were used in this study. Cronbach's alpha values for "P" statements exceeded 0.85 which indicated that they were in acceptable range (equal to or exceeding 0.80). Kolmgorov-Smirnov values of each "P" statement surpassed 0.05 indicating normal distribution. The lowest (4.74) and highest (6.17) scores of these "P" statements were significantly different ( $p=0.05)$ which indicated some successful targets were harder to achieve than others. The performance with the highest score was "the firm has received a number of food safety standards, such as GMP. HACCP. ISO22000, BRC." However, the "P" statement with the lowest score referred to was "The rejection on delivered products declined continuously in the past 3 years." The average performance score was as high as 5.86 indicating that the respondents' performance was good except for the fact that the rejection of delivered products were not on the decline.

Table 5: Correlation matric between food manufacturers' characteristics, organizational knowledge and skills, managerial attitudes, and performances

\begin{tabular}{|c|c|c|c|c|c|c|c|}
\hline & $\begin{array}{c}\text { Foreign } \\
\text { ownership }\end{array}$ & $\begin{array}{c}\text { Firm } \\
\text { Age }\end{array}$ & $\begin{array}{c}\text { Export } \\
\text { orientation }\end{array}$ & Firm size & $\begin{array}{l}\text { Knowledge } \\
\text { and skills }\end{array}$ & $\begin{array}{c}\text { Managerial } \\
\text { attitudes }\end{array}$ & Performances \\
\hline Foreign ownership & 1 & .008 & .003 & .009 & .000 & .049 & .031 \\
\hline Firm age & & 1 & .0187 & $.0216^{*}$ & .028 & .043 & .101 \\
\hline $\begin{array}{l}\text { Export } \\
\text { orientation }\end{array}$ & & & 1 & $.213 *$ & .108 & .071 & $.115^{* *}$ \\
\hline Firm size & & & & 1 & .008 & .065 & .105 \\
\hline $\begin{array}{l}\text { Organizational } \\
\text { Knowledge \& Skills }\end{array}$ & & & & & 1 & $.223^{*}$ & $.673 * *$ \\
\hline $\begin{array}{l}\text { Managerial } \\
\text { attitudes }\end{array}$ & & & & & & 1 & $.691 * *$ \\
\hline Performance & & & & & & & 1 \\
\hline
\end{tabular}

Hint: $* p<=0.05 * * p<=0.01 * * * p,=0.001$ 
There were some significant $(\mathrm{p}<0.05)$ associations between firms related data. Firm age was positively correlated with firm size. It was indicated that the length of time firms have spent in their businesses led to business expansion (increased size of the firm). Export orientation was positively correlated with firm size and additionally, it was significantly $(p<0.05)$ and positively associated with food safety performance. Managerial attitudes were also correlated with organizational knowledge and skills, and performance. In other words, firms with better managerial attitudes were likely to have better organizational knowledge and skills as well as higher levels of food safety performances. Unsurprisingly, respondents with higher organizational knowledge and skills were likely to have better food safety performance.

Table 6: Multiple regression of organizational food safety performances

\begin{tabular}{|l|c|c|c|}
\hline \multicolumn{1}{|c|}{ Variables } & $\begin{array}{c}\text { Unstandardized } \\
\text { Coefficients }\end{array}$ & $\begin{array}{c}\text { Standardized } \\
\text { Coefficients }\end{array}$ & P Value \\
\hline Constant & 1.496 & - & $0.000^{* * * *}$ \\
\hline Firm size & 0.000 & 0.053 & 0.984 \\
\hline Firm age & 0.002 & 0.068 & 0.211 \\
\hline Firm trade orientation & 0.003 & 0.095 & 0.185 \\
\hline Foreign Ownership & 0.015 & 0.137 & 0.157 \\
\hline Organizational Knowledge \& Skills & 0.296 & 0.335 & $0.000^{* * * *}$ \\
\hline Managerial Attitudes & 0.397 & 0.405 & $0.000^{* * *}$ \\
\hline F-test & 68.753 & \\
\hline R-Square & \multicolumn{2}{|c|}{0.515} \\
\hline
\end{tabular}

Hint: $* p<=0.05 * * p<=0.01 * * * p,=0.001$

Table 6 shows the multiple regression of organizational food safety performance on some independent variables (firm age, firm size, foreign ownership, export orientation, organizational knowledge and skills, and managerial attitudes). The results indicated that only two main variables, organizational knowledge and skills and managerial attitude, positively and significantly affected organizational food safety performance at $99.99 \%$ confidence level $(p<0.001)$. Of these two independent variables, the most highly influential determinants of organizational food safety performance were managerial attitudes towards food safety issues and organizational knowledge and skills, respectively. The model was valid from the high F-test score and could be used to explain organizational food safety performance of 51.5\%. Surprisingly, firm characteristics, such as firm size, firm age, export orientation, and foreign ownership, did not significantly $(P<0.05)$ determine food safety performance even though the coefficients of these four elements of firms' characteristics were positive as hypothesized.

\section{DISCUSSION AND CONCLUSION}

\subsection{Discussion}

The result of statistical analysis indicated that food safety performance in food manufacturing firms could be predicted by organizational knowledge and skills and managerial attitudes regarding food safety. Moreover, by observing standardized coefficients of the two independent variables, managerial attitudes towards food safety slightly played more important role than organizational food safety knowledge and skills. This findings are compatible with KAP model in food safety literature. However, a lot of academic papers with KAP model were generally conducted in a single factory using employees as unit of analysis and KAP model was generally tested in food service industry [0] [7] [8] [9] [10] [11] [12] [13] [19] [20]. Therefore, general KAP model was related to employee's knowledge, employee's attitude and employee's performance (personal level). Our research tried to examine food safety performance using a firm as unit of analysis (organizational level). We could learn that KAP model could be correctly implemented even in macro level which was organizational level and also in food manufacturing firms.

The research revealed that firm size, firm age, firm trade orientation, and foreign ownership did not significantly affect or promote food safety performance of food manufacturing firms even though the statistical results signified that there were positive relationship between food safety performance of the firm and these characteristics of the firm. The findings generally support the notion that regular food safety training is still important to the firm's food safety performance because food safety training could provide the firm's employees with food safety knowledge and skills. Another major powerful independent variable was managerial attitudes towards food safety. With the higher level of such positive attitudes towards food safety, 
the firm's managers would strengthen the degree and the likelihood they were going to support budget and all necessary equipment to ease food safety difficulties, to perceive food safety as priority, to perform as a role model, and to lead employees to comply with food safety rules and regulations. Therefore, managerial attitudes towards food safety significantly influenced the organizational food safety performance.

The research indicated that firms with high level of food safety knowledge and skills as well as high degree of good managerial attitudes towards food safety would have their food safety performance as a result disregarding size, age, foreign ownership, and export orientation. The findings were consistent with some previous research works such as food safety knowledge and skills [4] [6] [20] [21] [22] [23] and top management attitude and intention [14] [15] [24]. However, the findings were not consistent with some previous research studies such as firm size [19] [25] [26] and export orientation [27].

\subsection{Limitation of the Study}

We used stratified random sampling technique in this research. However, due to resource and time limitation, finally there were 326 respondents answering the questionnaire. Also, we aimed to focus on only medium and large-sized manufacturing firms in Thailand. Thus, we were recommended to extend or expand the topic in the future research.

\subsection{Future Study}

Most of the studies which investigated the KAP model were largely conducted in the US, Europe, or major countries in Asia. Owing to various differences such as cultures, standard of living, social expectation, and technological advancement, it was difficult to generalize the findings to other countries. Many studies in the past were generally conducted using an employee as unit of analysis. However, this study is differently conducted with a firm as unit of analysis. As far as we know, this research was the first study that investigated the KAP model with a firm as unit of analysis in South East Asia. Food manufacturing sector in Thailand and South East Asia region is moving forward quickly in term of GDP and food safety plays a vital role in food industries. Therefore, it is worth conducting researches.

The study showed that organizational knowledge and skills as well as managerial attitudes regarding food safety significantly resulted in food safety performance in food manufacturing firms in Thailand. We propose that there shall be further research on this topic in any other countries in Asia. Moreover, it is worth examining to understand the effects of organizational knowledge and skills and managerial attitudes on food safety performance in food service industry. Given that the respondents in this research were selected from medium and large-sized food manufacturing firms, future research could embrace small-sized food manufacturing firms as extending group of future research target. Last but not least, we cordially hope that future research would bring a lot of benefits from the more understanding of food safety related to human issues for quality food safety management and its implementation.

\subsection{Conclusion}

The results conformed to the notions of the KAP model. Unlike almost all the studies conducted for evaluation of knowledge, attitudes, and practices based on an individual workers (micro perspective), this study focused on organizational knowledge, managerial attitudes and food safety performance, by focusing on the entire firm (macro perspective). Organizational knowledge and skills and good managerial attitude towards food safety are crucial aspects of generating a progressive food safety performance because food safety knowledge and skills, as well as managerial attitudes, may improvement food safety understanding, elevate managerial support, encourage the escalation in the level of workers' desirable behavior, decrease risk of foodborne disease, reduce flawed products, and satisfy customers' needs. We recognize the need for a more comprehensive study to evaluate the relationship between organizational knowledge and skills, managerial attitudes, and performances regarding food safety among food manufacturing firms in other nations. Pursuing in smaller-sized firms and in food service industry is also recommended. The results of this study indicate that there is a need for an organization to have food safety knowledge and skills in order to maintain food safety knowledge that leads to food safety performance. The results also suggest that positive managerial attitudes towards food safety are essential to achieve improved and high levels of food safety in food manufacturing firms.

\section{ACKNOWLEDGEMENTS}

The authors are grateful to "The 90th Anniversary of Chulalongkorn University Fund (Ratchadaphiseksomphot Endowment Fund)" and for the financial support to this project. We appreciate the kind cooperation of firms in conducting this study. We are obliged to food safety experts for their valuable engagement and contribution. We are also very grateful to external experts and staff at Chulalongkorn University and Suan Dusit University for their help. Last, we want to offer special thanks for Witaya Siripanwattana for his unstinting support. 


\section{REFERENCES}

[0] C. J. Griffith, K.M. Livesey, D.Clayton, "Food safety culture: the evolution of an emerging risk factor?" British Food Journal, vol. 112, pp.439-456, 2010.

[1] World Health Organisation, World health statistics c2015 [cited at 2015 November 19]. Available from: http://www.who.int/gho/publications/world_health_statistics/2015/en/

[2] M. Ansari-Lari, S. Soodbakhsh, L. Lakzadeh, "Knowledge, attitudes, and practices of workers on food hygienic practices in meat processing plants in Fars, Iran," Food Control, vol. 21, pp.260-263, 2010.

[3] F.L. Bryan, "Risks of practices, procedures and processes that lead to outbreaks of food borne disease," Journal of Food Protection, vol. 51, pp.663-673, 1988.

[4] C. Buccheri, C. Mammina, S.Giammanco, M.Giammanco, M. La Guardia, A. Casuccio, "Knowledge, attitudes, and selfreported practices of food service staff in nursing homes and long-term care facilities," Food Control, vol. 21, pp.13671373, 2010.

[5] J.E.Ehiri, G.P. Morris, "Hygiene training and education of food handlers: does it work?" Ecology of Food and Nutrition, vol. 6, pp.341-345, 1994.

[6] S-H. Park, T-K. Kwak, H-J. Chang, "Evaluation of the food safety training for food handlers in restaurant operations," Nutrition Research Practice, vol. 4, no. 1, pp.58-68, 2010.

[7] I.F. Angelillo, N.A.Viggiani, L.Rizzo, A.Bianco, “ Food handlers and food borne disease: knowledge, attitudes, and reported behavior in Italy,” Journal of Food Protection, vol. 63, pp.381-385, 2000.

[8] S.P.Luby, J.Jones, J. Horan, "A large salmonellosis outbreak associated with a frequently penalized restaurant," Epidemiology and Infection, vol. 110, pp.31-39, 1993.

[9] E.A. Tayler, "Is food hygiene training really effective?" Journal of Environmentally Health, vol. 104, pp.275-276, 1996.

[10] B. Ball, A.Wilcock, S. Colwell, "Tool for measuring food safety climate," Journal of Food Protection, vol. 73, no. A, pp.84, 2010.

[11] T. Laikko-Roto, M. Nevas, "Restaurant business operators on knowledge of food hygiene and their attitudes towards official food control the hygiene in their restaurants," Food Control, vol. 43, pp.65-73, 2014.

[12] L.S. Soares, R.C.C. Almeida, E.S. Cerquera, J.S. Carvalho, I.J. Nunes, "Knowledge, attitudes and practices in food safety and the presence of coagulase-positive Staphylococci on hands of food handlers in the school of Camacari, Brazil," Food Control, vol. 27, pp.206-213, 2012.

[13] D.M. Rennie, "Health education models and food hygiene education," Journal of the Royal Society of Healths, April, pp.75-79, 1995.

[14] I. Ajzen, M. Fishbein, "Attitude-behavior relations: A theoretical analysis and review of empirical research," Psychological Bulletin, vol. 84, pp.888-918, 1977.

[15] I. Ajzen, M. Fishbein, “The influence of attitudes on behavior,” In D.B. Albarracin, T. Johnson, M. P. Zanna (Eds.), The handbook of attitudes, Mahwah, New Jersey, USA, pp.173-221, 2005.

[16] J. Pichiler, J. Ziegler, U.Aldrian, F. Allerberger, "Evaluation level of food knowledge on food safety among food handlers from restaurants and various businesses in Vienna, Austria 2011/2012," Food Control, vol. 35, pp.33-40, 2014.

[17] S. Wikstrom, R.Norman, "Knowledge and value: A new perspective on corporate transformation,” T.J Press (Padstow) Ltd. Padstow, Cornwall, Great Britain, 1994.

[18] Bank of Thailand, Thailand statistics, 2016 [cited at 2016 November 15]. Available from: http://www.bot.or.th/Thai/statistics 2016

[19] E.A.Taylor, K.Kane, "HACCP and SMEs," Food Control, vol. 16, no. 10, pp.833-9, 2005.

[20] S.Y. Deodhar, Motivation for and cost of HACCP in Indian food processing industry, Working paper, Center of Management in Agriculture, Indian Institute of Management, Ahmedabad (IIM-A), 2003. 
[21] C.Yapp, R.Fairman, "Factor affecting food safety compliance within small and medium-sized enterprises: implications for regulatory and enforcement strategies," Food Control, vol. 17, no. 1, pp.42-51, 2006.

[22] J.C.Buzby, T. Roberts, "The economics of enteric infections: human food borne disease costs," Gastroenterology, vol. 136, no. 6, pp.1851-1862, 2009.

[23] I.Nonaka, A dynamic theory of organization knowledge creation. Organization Science, USA, 1994.

[24] P.Sohrap, "Sohrab adoption of food safety management system - a challenge for dairy industry in India," Beverage \& Food World, vol. 27, no.7, 2000.

[25] M.P. Mortlock, A.C.Peter, C.J.Griffith, "Food hygiene and hazard analysis critical control point in the United Kingdom food industries: Practices, perceptions, and attitudes," Journal of Food Protection, vol. 62, no. 7, pp.786-92, 1999.

[26] R.Fairman, C.Yapp, "Consumer with food safety legislation in small and micro-business: enforcement as an external motivator," Journal of Environmental Health Research, vol. 3, no. 2, pp.44-52, 2004.

[27] A. Pornlert, K. Suwimon, C.Araya, T.Eunice, "Factors influencing food safety management system adoption in Thai food-manufacturing firm model development and testing," Business Food Journal, vol. 111, no. 4, pp.36-375, 2009.

[28] Ministry of Public Health, Food safety situation in Thailand, Food safety report, Thailand, 2016. 